\title{
Rectennas for RF Energy Harvesting and Wireless Power Transfer: a Review of Antenna Design
}

\author{
Mahmoud Wagih, Student Member, IEEE, Alex S. Weddell, Member, IEEE, Steve Beeby, Senior Member, IEEE
}

\begin{abstract}
Radio frequency energy harvesting (RFEH) and radiative wireless power transfer (WPT) have attracted significant interest as methods of enabling battery-free sustainable wireless networks. Rectifying-antennas (rectennas) are the corner-stone of WPT and RFEH systems and critically affect the amount of DC power delivered to the load. The antenna element of the rectenna directly impacts the radiation to $\mathrm{AC}$ harvesting efficiency, which can vary the harvested power by orders of magnitude. In this paper, antenna designs employed in WPT and ambient RFEH applications are reviewed. Reported rectennas are categorized based on two main criteria: the antenna-rectifier impedance bandwidth and the antenna's radiation properties. For each criteria, the Figure of Merit (FoM) is identified, for different applications, and reviewed comparatively.
\end{abstract}

Index Terms-Antenna, Gain, Internet of Things, Microstrip antennas, Rectenna, RF Energy Harvesting, RF Power Transfer, Wearable Antenna

\section{INTRODUCTION}

Tesla proposed Wireless Power Transfer (WPT) in the 1900s as a mean of transferring thousands of horse-power [1]. The term "rectenna", describing an antenna connected to a rectifier for harvesting Radio Frequency (RF) power, emerged in the 1950s for space microwave power-beaming applications and for powering autonomous drones [2]. Omni-directional longrange WPT has been hindered by the physical characteristics of the propagation medium, air. Thus, commercial WPT has been mostly limited to near-field non-radiative power transfer for wireless consumer electronics charging, or short-range radiative Radio Frequency Identification (RFID) [3].

As the power consumption of semiconductor devices and wireless sensor nodes continuously scales down, it became more feasible to power sensor nodes using ambient Radio Frequency Energy Harvesting (RFEH), or using distributed low-power omni-directional transmitters [4], [5]. An ultra-low power wirelessly-powered system is typically composed of the RF-harvesting front-end, DC power and storage management, and a low-power microprocessor and transceiver.

Fig. 1 shows the architecture of a RFEH wireless node, and the commonly reported implementations of the RF-frontend. The end-to-end efficiency of a wirelessly-powered system, as well as, the architecture of a Simultanious Wireless Information and Power Transfer (SWIPT) network are dependent on the performance on individual components such as: the antenna, rectifier and power management circuit. Multiple

This work was supported by the European Commission under H2020EU.1.4.1.2. (Corresponding author: Mahmoud Wagih)

The authors are with the School of Electronic and Computer Science, University of Southampton, Southampton, SO17 1BJ, U.K. (email: mahm1g15@ecs.soton.ac.uk)

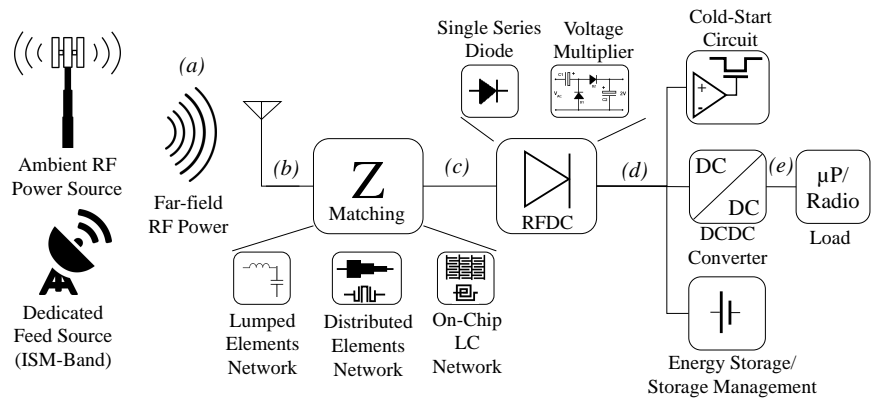

Fig. 1. System architecture of a RFEH wireless node, showing the power sources and conversion stages, as well as commonly reported implementations.

TABLE I

POWER CONVERSION STAGES IN A RFEH SYSTEM

\begin{tabular}{|c|c|c|c|}
\hline $\begin{array}{l}\text { Conversion } \\
\text { stage }\end{array}$ & Power source & Focus element & $\begin{array}{l}\text { Literature } \\
\text { surveys }\end{array}$ \\
\hline$a-b$ & $\begin{array}{l}\text { Radiated RF } \\
\text { plane wave }\end{array}$ & $\begin{array}{l}\text { Antenna radiation } \\
\text { characteristics }\end{array}$ & This survey \\
\hline$b-c$ & $\begin{array}{l}\text { RF guided } \\
\text { wave }\end{array}$ & $\begin{array}{c}\text { Antenna and } \\
\text { matching network } \\
\text { bandwidth }\end{array}$ & $\begin{array}{c}\text { This survey, } \\
2013[4], 2018 \\
{[8], 2019[10]}\end{array}$ \\
\hline$c-d$ & $\begin{array}{l}\text { Z-matched RF } \\
\text { wave }\end{array}$ & $\begin{array}{l}\text { Rectifier topology } \\
\text { and technology }\end{array}$ & $\begin{array}{c}2013[4], 2014 \\
{[6], 2016[9],} \\
2018[8]\end{array}$ \\
\hline d & $\begin{array}{l}\text { Unregulated } \\
\text { DC power }\end{array}$ & $\begin{array}{c}\text { Power } \\
\text { management } \\
\text { circuitry }\end{array}$ & $\begin{array}{c}2015 \text { [7], } 2016 \\
\text { [9] }\end{array}$ \\
\hline $\mathrm{e}$ & $\begin{array}{c}\text { Regulated DC } \\
\text { power }\end{array}$ & $\begin{array}{l}\text { Load, network } \\
\text { architecture }\end{array}$ & $\begin{array}{c}2013[4], 2014 \\
{[5]}\end{array}$ \\
\hline
\end{tabular}

literature surveys have been carried out focusing on different components of the system. Table I outlines the power conversion stages, the key component for efficient power conversion, and the relevant literature surveys focusing on each part. Recent surveys focused on the power conversion techniques [4], [6], [7], rectifier topologies [7], [8], or RFEH from a networking perceptive [5], [9]. However, antenna design for RFEH has not been considered as a key parameter in reported reviews. To illustrate, while some surveys considered the antenna's bandwidth and efficiency from a holistic perspective, or specific antenna designs for niche applications such as miniaturized or wearable antennas [8], [10], no detailed analysis has been presented on the impact of certain antenna parameters on the power reception and conversion efficiency.

This survey reviews antenna design techniques in a rectenna, aiming to distinguish the RFEH- and WPT-specific antenna design challenges from standard antenna design for communications. Antennas are compared from two perspectives, endto-end impedance matching, and radiation properties, in each 

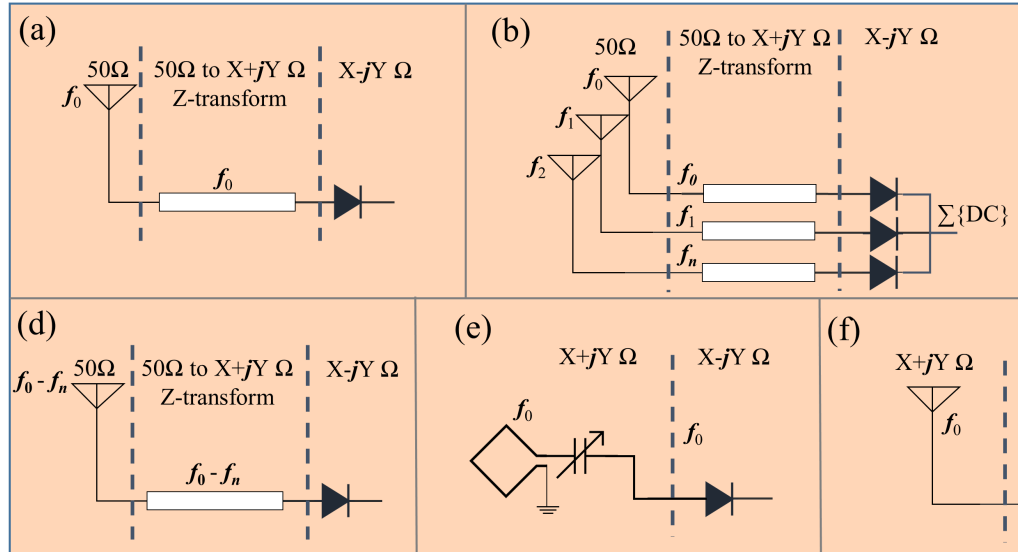

(e)

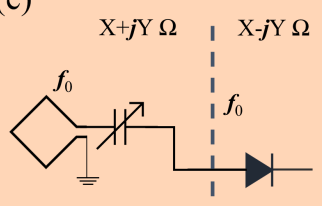

(c)

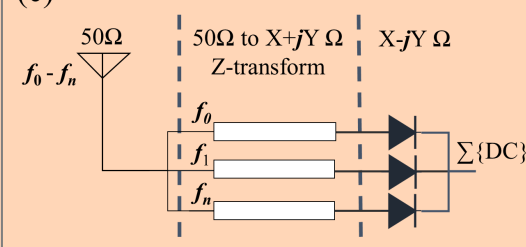

(f)

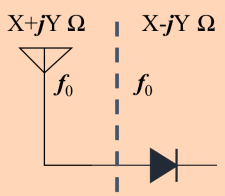

(g)

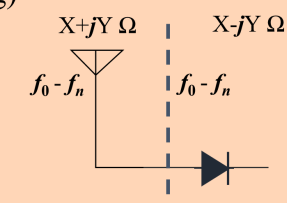

Fig. 2. Rectenna topologies from a bandwidth and impedance matching perspective. (a): Single band rectenna with standard antenna. (b): Multi-band rectenna (formed of multiple mutually coupled antennas) with one rectifier and matching network per band. (c): Broadband rectenna with multiple RF-ports and separate matching networks for each band. (d): Broadband rectenna with a broadband antenna and a broadband matching network. (e): Single band rectenna using an electrically small antenna directly matched to the rectifier. (f): Single band electrically large antenna with complex impedance to conjugate the rectifier. (g): Broadband rectenna with complex impedance to conjugate the rectifier over a range of frequencies. The dashed line represents the measurement plane where a $S_{11}<-10 d B$ bandwidth needs to be maintained.

context, the figure-of-merit (FoM) is identified and reviewed in state-of-art antennas. Section II defines the bandwidth and matching challenge in rectennas, and compares the reported approaches to fulfilling the bandwidth requirements of a rectenna. Section III reviews rectennas based on $50 \Omega$ antennas, with the matching network design in section IV. Section $\mathrm{V}$ reviews antenna-rectifier co-design and matching network elimination techniques. Finally, radiation properties of rectennas are reviewed in section VI.

\section{BANDWIDTH AND MATCHING:

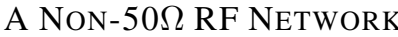

The standardization of the characteristic impedance to the $50 \Omega$ constant has been derived as a compromise between attenuation and power-handling in the early-days of microwave engineering [11]. In antennas, the impedance bandwidth, is defined as the range of frequencies where the reflected power is less than $10 \%\left(S_{11}<-10 d B\right)$. This has been traditionally referenced to a $50 \Omega$ source, due to the fact that Low-Noise Amplifier (LNA), Power Amplifiers (PA) and detectors are conventionally designed with $50 \Omega$ input impedance matching.

In rectennas, where the antenna's output is fed directly into a rectifier, the non-linearity of the diode results in a highly-varying input impedance, with a dominant capacitive component [12], [13]. Assuming a $50 \Omega$ antenna is used, the main challenge lies in designing an additional RF matchingnetwork to transform the input impedance to the rectifier's at the frequencies of interest, and optimizing it for a certain power level. In this case, an end-to-end impedance bandwidth is required to ensure efficient RF to DC conversion. Thus, although an antenna could achieve a theoretical infinite or ultra-broad bandwidth using periodic elements or selfcomplimentary geometry, the rectenna's bandwidth will be bottlenecked by the rectifier's matching network.

Multiple rectenna topologies have been presented to maximize the power transfer between the antenna and the rectifier, through minimizing reflection, for single- and multi-band harvesting or WPT. Figure 2 shows a summary of the reported rectenna topologies categorized by their impedance matching architectures. Examples of high performance rectennas, in terms of end-to-end bandwidth (the FoM in this case), from each category are shown in Table II.

While WPT from a dedicated feed and ambient RFEH are distinct rectenna applications, from a bandwidth perspective, achieving an end-to-end match between the antenna, the rectifier and the load is fundamental to achieving high Power Conversion Efficiency (PCE). Nevertheless, WPT rectennas have been more focused on achieving a higher-Q match (lower $\left.S_{11}\right)$ to improve the single-tone PCE for certain power levels (topologies a, e and f), hence, in single-tone WPT may not be a FoM on its own. However, a broad bandwidth in single-tone WPT improves the systems immunity to detuning, fabrication imperfections and packaging parasitics. On the other hand, RFEH rectennas have prioritized multi-band operation, due to the often low Power Spectral Density (PSD) in single bands, falling into topologies b-d and g.

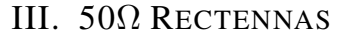

\section{A. Single-Band $50 \Omega$ Antennas in Rectennas}

The antenna design of $50 \Omega$ single band rectennas (topology A) has been based mostly on standard antenna designs, such as a Linearly-Polarized (LP) or a Circularly Polarized (CP) radiator patch over a ground plane [14], [23]-[26], dipole antennas [15], [27] and inverted-F monopoles [28]-[31]. Differential single-band rectennas have been based on multiple antenna elements configured as an array with DC combining [23], or hybrid DC and RF combining of multiple patch elements [32]. The effect of size reduction on the rectenna's PCE has been discussed in [33].

As many of the presented $50 \Omega$ antennas are single band, which meets the requirements of single-tone WPT, when ambient multi-band RFEH is sought, multiple single-band 
TABLE II

COMPARISON OF RECTENNAS BASED ON THEIR IMPEDANCE MATCHING ARCHITECTURE

\begin{tabular}{ccllll}
\hline Lit. & Topology & Antenna & Matching & Frequency bands (GHz) & $\begin{array}{l}\text { Fractional Bandwidth (rect- } \\
\text { enna) FoM }\end{array}$ \\
\hline \hline $2018[14]$ & A & Narrow-Band Patch & Single-band tapered line & 2.45 (single) & $4 \%$ \\
\hline $2013[15]$ & B & Single-band tapes & Single-band LC & $0.5,0.9,1.8,2.1$ & $7 \%, 5 \%, 3 \%, 4-5 \%$. \\
\hline $2018[16]$ & B and C & $\begin{array}{l}\text { Broadband slot, single band } \\
\text { slot }\end{array}$ & $\begin{array}{l}\text { T/Pi networks } \\
\text { diode/band) }\end{array}$ & (single & $0.9,2,2.55$ \\
\hline $2016[13]$ & C & $\begin{array}{l}\text { Frequency-independent Log- } \\
\text { periodic }\end{array}$ & Transmission-line match & $0.55,0.75,0.9,1.8,2.3$ & $9 \%^{*}, 3 \% *^{*}, 2.3 \%, 2.2 \%, 2.2 \%$ \\
\hline $2013[17]$ & D & Broadband Yagi-Uda array & $\begin{array}{l}\text { 8th-order LC (voltage dou- } \\
\text { bler/band) }\end{array}$ & $1.8,2.1$ & $4 \%, 3 \%$ \\
\hline $2014[18]$ & E & High-Q loop & Weighted capacitor bank & 0.868 & $6.9 \%$ \\
\hline $2016[19]$ & F & High-Z Dipole & N/A & 0.55 & $21.1 \%$ \\
\hline $2017[20]$ & G & High-Z Multi-band Dipole & N/A & $0.95,1.85-2.4$ & $2 \%, 30 \%^{*}$ \\
\hline
\end{tabular}

*Bandwidth at $S_{11}<-6 d B$
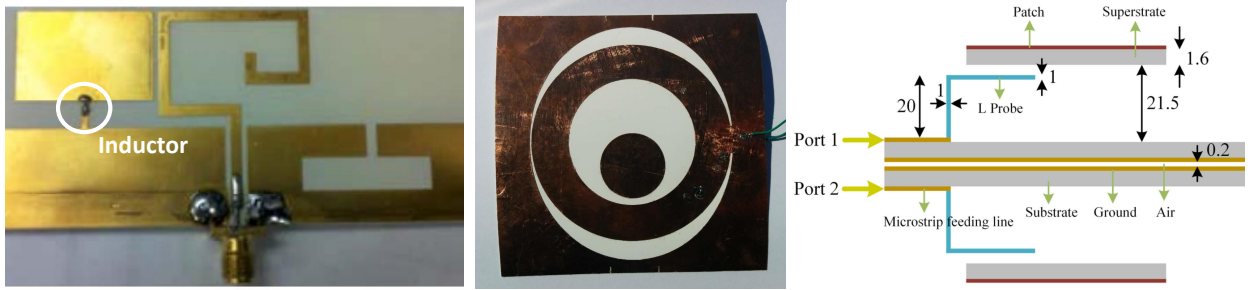

Fig. 3. Multi-band UHF RFEH antennas: Triple band antenna with a lumped inductor and three radiator elements [21] (left), triple band slotted patch [16] (center), and L-probe-fed dual-band patch [22] (right)

antennas have been combined to form multi-band rectennas with suppressed mutual coupling (topology B) [15], [28], with independent DC combining, after the power management circuit stage, making it entirely isolated from the RF harvesting and conversion circuit, requiring multiple power management circuits for each bands, which may decrease the efficiency of the boost converters [14], due to the low DC power from individual bands.

\section{B. Multi- and Broad-band RFEH Antennas}

Ambient RFEH is usually associated with multi-band harvesting, thus, multiple methods of improving the bandwidth of standard antenna designs, or methods of forming dual or triple-band antenna arrays have been presented. In this section, bespoke antenna design for RFEH is reviewed, along with classic multi-band antennas with the potential of being employed as rectennas. In this context, the terms "multiband" and "broadband" antennas are differentiated through the continuity of their bandwidth $\left(S_{11}<-10 d B\right)$ outside the bands of interest.

Coplanar-Waveguide (CPW) monopoles, occupying smaller areas than their microstrip patch antenna counterpart at the same frequency, and producing a LP or a CP wave, are commonly used in broadband ambient rectennas [34]-[36]. A reflector plane can be used for increased isolation, and improved gain resulting in a similar radiation pattern to patch antennas [36]. Slotted-CPW antennas were used to improve the impedance-bandwidth across multiple bands such as the 1.8-2.7 GHz [35] or 1-3 GHz [34], [37].

Slot rectennas, with aperture-proximity feed were designed to have increased bandwidth, as well as multiple proximity feeds for different rectifiers and matching networks targeting different bands. [16], [38], [39]. Patch rectennas have also been presented for dual-band operation using asymmetric corner trimming resulting in dual-resonance [39]. Figure 3 shows some of the reported multi-band antennas utilizing more than one bandwidth improvement technique.

Conventional broadband antenna designs, including frequency-independent antennas, have been used in ambient RFEH as well as proposed for mmWave applications [40]. Spiral antennas: a single element textile rectenna with a single band matching network [41], a spiral array [42], and a log-periodic antenna [13] have been presented. A triangular spiral antenna has also been presented for harvesting energy from 1-3 GHz [43]. A spiral antenna, with unfolded dipole ends was presented for dual-band operation at $900 \mathrm{MHz}$ and the Ultra-Wide Band (UWB) (3-5 GHz) bands [44]. Ref. [45] presents triple band operation using a multi-port rectenna formed of an array of "pixel" elements, with DC combining, with the "pixel" connections optimized through simulation to tune the antenna, the "pixel" rectenna has been compared to $\lambda / 4$ monopoles .

\section{Antenna-Rectifier ImPedance Matching}

Matching the $50 \Omega$ antenna to a non-linear rectifier presents a challenge due to the wide variation in its input impedance with frequency. In topologies A and B (Fig. 2), a common matching network topology is LC matching using lumped components [46], [47], however, the fractional bandwidth is typically lower than most communication bands [15]. Single band stub matching has been commonly used at sub- $6 \mathrm{GHz}$ microwave [14], [45], [48] as well as at milli-meter Wave 
(mmWave) bands [49], [50], usually paired with RF-short quarter-wave stubs at the fundamental frequency and the $2^{\text {nd }}$ harmonic. Therefore, the reported mmWave rectennas have inherently narrow band due to their PCE bandwidth being bottle-necked by the harmonic rejection at the outuput, which makes them specific to single-tone WPT applications in the $24 \mathrm{GHz}$ license-free band. A comparison of lumped and distributed stub matching has been reported in order to numerically defining a maximum PCE of a rectenna [51].

Rectennas in topologies $\mathrm{C}$ and $\mathrm{D}$ have been presented with more complex matching networks. Full-distributed-line matching networks have been presented for broadband operation [52], [53], with an RF-block-DC-short (DC-pass filter) at the output port [17] or a DC-block capacitor acting as a return path for the diode's harmonics [22]. Rectifier components, such as capacitors in a voltage doubler, have been replaced in [52] by Printed Circuit Board (PCB) interdigitated capacitors, synthesized using commercial Electronics Design Automation (EDA) tools. Other reported broadband rectenna matching networks combine lumped components, for matching the lower frequencies, and distributed elements for creating RF shorts at the input [54]. Varying the load's observed input impedance by the source, known as source-pull technique, has been utilized to design a broadband rectifier of $57 \%$ fractional bandwidth (1.25 to $2.25 \mathrm{GHz})$ with up to $10 \%$ higher PCE compared to a lumped or distributed line matching network [55]. While matching networks have commonly been designed to match the antenna across its full $50 \Omega$ bandwidth, in [41], [56] broadband antennas have been connected to narrow-band rectifiers.

Hybrid lumped and distributed elements matching networks have been widely used in topologies C and D [13], [16], [22], [54], with series inductors and capacitors being the most commonly utilized lumped components [35]. These avoid complex structures such as interdigitated capacitors which require more accurate modeling and fabrication than standard microstrip lines.

The input power to the rectifier affects the input impedance due to the diodes' non-linearity. Therefore, rectennas have been designed to maximize the PCE for specific input power levels as well as load impedances [14], [45]. In [13], the matching network for the six band rectenna, following topology $\mathrm{C}$, has been designed to match the rectifier at power levels from $-30 \mathrm{dBm}$ to $-10 \mathrm{dBm}$ and for load impedances from 1 to $100 \mathrm{k} \Omega$, based on a complimentary conjugate resistance compression network. Moreover, as a result of the predominately capacitive high impedance of the diodes at sub-3 GHz frequencies, broadband rectennas with eliminated matching networks [20], [57], [58], or minimized simplified matching circuits [59], have been focused on $P_{R F}>0 d B m$, and frequencies higher than $1 \mathrm{GHz}$ [58]-[61] due to the lower capacitive impedance of the diode enabling a good match with the antenna, avoiding designing antennas with input reactance $>1000 \Omega$.

Adaptive, or reconfigurable, impedance matching has been presented in Complimentary Metal Oxide Semiconductor (CMOS) rectennas, where the matching network is formed of an on-chip capacitor bank and inductors [62]. Static CMOS matching networks have also been presented for standard $50 \Omega$ antennas [62] as well as co-designed loop antennas [18], [63]. In [64], a passive CMOS power-detector has been used to control the switches directing the antenna's output to different rectifiers and matching networks based on the available power. A design-time reconfigurable matching network has been presented using lumped adjustable capacitors, tuned by trimming while measuring the input impedance using a Vector Network Analyser (VNA) [65]. On-board switches, controlled by an external micro-controller, were utilized in [66] to tune the on-PCB matching network capacitors at 900 $\mathrm{MHz}$, demonstrating up to $10 \%$ performance improvement. In a reconfigurable microstrip matching network, a Field-Effect Transistor (FET) switch has been used to tune matching stubs for dual-frequency operation [67].

\section{Antenna And Rectifier Co-DESIGN}

Rectennas following topologies E-G in figure 2 are characterized by the antenna's direct match to the rectifier, instead of the $50 \Omega$ standard, requiring a minimized or eliminatedmatching circuit to deliver power to the rectifier. This section reviews state-of-the-art rectennas employing non-50 $\Omega$ antennas, in addition to the advantages of matching-network-less rectennas.

\section{A. Electrically Small Antennas}

LC resonant loop antennas have been widely used in applications where the system's size is critical. At sub- $1 \mathrm{GHz}$ frequencies, where the wave-length could result in a standard distributed-elements antenna occupying more space than the system's overall dimensions, applications such as fullyintegrated transceivers for body-implants particularly benefit from using electrically small antennas for WPT [68].

The highly inductive impedance, near resonance, of a smallantenna can be utilized to directly conjugate the rectifier [69], or with an additional on-chip capacitive matching network [18], [70]. Electrically small antennas, down to $k a=0.645$, compared to $k a=5.91$ in a normal dipole $\left(k a=2 \pi r / \lambda_{0}\right)$, have been reported for sub-1 GHz WPT with LP and CP [69], using Huygens dipole antennas [71].

Multiple on-chip LC coils for radiative WPT have been presented for microwave and sub-1 $\mathrm{GHz}$ fully-integrated rectennas. In a fully-integrated $915 \mathrm{MHz}$ CMOS rectenna, a dipole antenna has been directly tuned to match a $3.4 \Omega$ source using slot-termination to inductively load the antenna [72]. CMOS rectennas with a Power Management Integrated Circuit (PMIC) and a LNA were also presented with onchip loop antennas in a standard Silicon-on-Insulator (SoI) chip [73]. A power-harvesting RFID $5.8 \mathrm{GHz}$ transceiver with an integrated coil-antenna has been presented for near-field powering [74]. A dual-band antenna, for $7 \mathrm{GHz}$ WPT and 1 $\mathrm{GHz}$ communication have been presented with on-chip tuning capacitors [75].

\section{B. Rectifier Conjugate Antennas}

As observed in [12], [13], the typical input impedance of the diode is highly capacitive, and therefore requires 


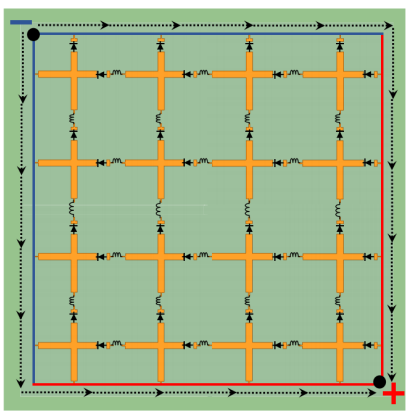

(a)

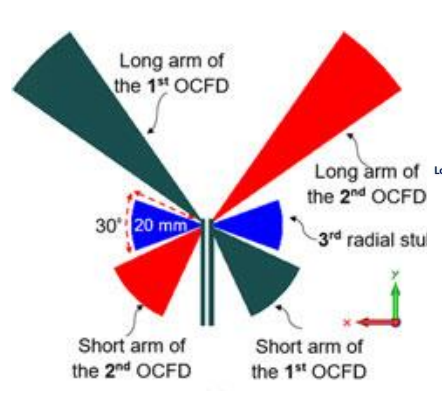

(b)

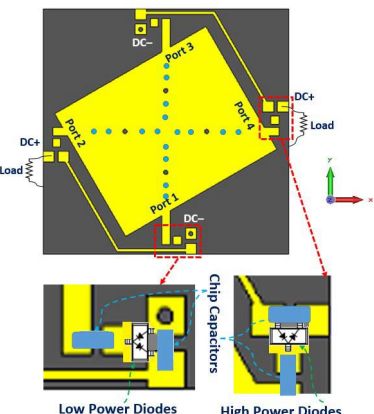

(c)

Fig. 4. Rectennas directly matching the diode's impedance: (a): $4 \times 4$ RFEH cross-dipole surface [58], (b): broadband inductive off-center fed dipole (OCFD) [20], (d): all-polarization frequency-selectable off-set patch [57]

an inductive antenna to directly conjugate the impedance. High impedance, inductive antennas have been widely used in RFID tags due to the chips' capacitive impedance [76]. Thus, a similar approach can be utilized to design a RFEH antenna to directly conjugate the rectifier's impedance. Dipole antennas, recently becoming a trend in complex-impedance RFID antennas [76], exhibit high impedance (resistance and reactance) near their resonant frequency. For example, [77] reports one of the earliest dipoles designed to match the resistance of the diode with a low-impedance load. However, only the resistance of the dipole is partially matched to the rectifier. A similar approach was reported when measuring the reception efficiency of polarization-independent arrays using a resistive load simulating the rectifier's real-impedance [78], [79], achieving an impedance bandwidth from 6 to $20 \mathrm{GHz}$ with respect to the purely-resistive dummy load in [79].

Inductive dipoles [19], [20], [80] have been used to match the high capacitance of the rectifier at the band of interest. In a folded dipole antenna, the dual shorted lines (dipole-folds), act as an impedance transformer allowing the design of very high impedance antennas [19]. Alternatively, the offset feed, [20], [57], is responsible for increasing the inductive reactance as well as the real impedance. Combining multiple offset dipole elements with imbalanced bow-tie radial stubs resulted in the dual-broadband high impedance of the antenna [20]. A hybrid filter-matching network structure has been incorporated in the antenna in [81] and a cross dipole array [82] represent the highest frequency direct antenna-rectifier matching rectenna (Ku band). Cross-dipole RFEH surface arrays have been also reported with a real impedance match [79], [83] or a complex impedance match to the rectifier [58]. Figure 4 shows some of the reported rectifier conjugate antennas.

Other antenna structures, such as dual-LP [51], [57] and $\mathrm{CP}$ patches [61] have also been used to directly conjugate the rectifier's impedance, providing higher gain compared to omni-directional dipoles. The off-center feed in [57] produces additional narrow-band resonances allowing three bands of operation, as opposed to a standard single-band patch. This approach demonstrates relatively high efficiency independent of the load resistance between $700 \Omega$ and $4500 \Omega$ at $P_{R F}>$ $0 \mathrm{dBm}$, the operation power choice enables easier matching due to the reduced capacitive impedance of the diode. A
TABLE III

Key RADIATION PROPERTIES IN WPT AND RFEH RECTENNAS

\begin{tabular}{llll}
\hline Parameter & Ambient RFEH & Dedicated WPT \\
\hline Gain & Insignificant [45] & FoM \\
\hline Beam-width & Wide & (Omni- & $\begin{array}{l}\text { FoM: Narrow, direc- } \\
\text { tirectional) }\end{array}$ \\
& Arbitrary: LoS \\
\hline LP/CP & Dual & Single-Pol, CP \\
& & \\
\hline
\end{tabular}

rectenna array exhibiting only a real-impedance match has been previously presented for a simpler antenna design [23].

\section{RADIATION PROPERTIES IN RFEH AND WPT}

The power received, $P_{R X}$ in the Friis model (1), by an antenna, at distance $d$ from the transmitter, is a direct function of the receiver and the transmitter gain $\left(G_{R X}, G_{T X}\right)$. While the gain, on its own is often regarded as a FoM, it does not provide a complete picture on the anticipated reception of the rectenna.

$$
P_{R X}(d)=P_{T X} G_{T X} G_{R X}\left(\frac{c}{4 \pi d f}\right)^{2}
$$

Antenna properties such as main-lobe directivity and polarization directly impact the amount of power harvested from an incident wave. Antenna radiation properties are the key parameter where ambient RFEH and WPT can be distinguished. While in both applications the propagation medium may be unknown, and its impact on the received wave needs to be considered, knowledge of the transmitting antenna can be exploited. Table III identifies the key parameters reviewed in this section, and their applicability to RFEH and WPT, distinguishing where how the FoM changes with application.

\section{A. Directivity and Gain}

In most RFEH and WPT applications, it is assumed that the direction of the incident radiation is unknown by the harvester, with no LoS path. In this effort, multiple antenna designs and placements have been investigated to maximize the received power from an unknown source, independent of main-lobe alignment between the transmitter and the receiver.

Omni-directional rectennas have been widely presented in ambient RFEH rectennas [15], [28]. In [15], [84], the PSD 


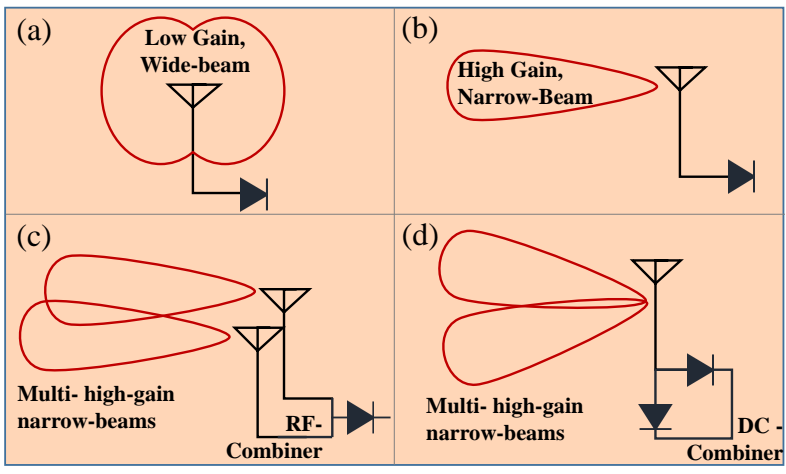

Fig. 5. Rectenna topologies based on the antennas' radiation patterns. (a): Omni-directional antenna. (b): High-gain directional. (c): Multi- high-gain beam antenna with RF combining. (d): Multi- high-gain beam with DC combining.

has been reported to vary based on the antenna's orientation. Nevertheless, the variation in power has not been explained and hence it is impossible to identify if the change is due to the antenna's radiation pattern, or due to a polarization mismatch.

High gain directional antennas and arrays have been widelyreported for microwave WPT and beaming [85], in addition to RFEH applications; improving the harvesting efficiency from low RF power-densities or overcoming the propagation losses. Yagi-Uda rectenna arrays [17], [86], bow-tie array [87], a spiral array [42], tightly-coupled-Vivaldi array [88], a CPW $\mathrm{CP}$ array [89] and a wide-area patch array [23] were among the scalable rectenna implementations for maximizing the incident power density, where the area permits. Other approaches to improve the antenna's gain included Substrate-Integrated Waveguide (SIW) techniques at microwave and mmWave bands, specific to WPT [90]-[92]. However, high-gain rectennas are characterized by narrow-beam width, making receiving arbitrarily-directed waves inefficient. An investigation into the number of antenna elements and ports concluded that higher directivity does not correspond to higher harvested power in ambient RFEH assuming a 3D random incident field, this has been validated through field measurements in urban environment [28]. Based on [28], high gain arrays can be restricted to WPT applications.

In the effort of porting the benefits of higher gain antennas to arbitrary RFEH, packaging or layout solutions have been utilized to overcome directionality problems. A double-patchantenna wrist-band was presented to harvest power from both directions, for ambient Wi-Fi RFEH [14]. Ambient cellular RFEH antennas have also been designed as 3D boxes [93], and printed or adhered to the walls of an enclosure [48], [94], [95], for reducing the system's area and enabling multi-direction harvesting. In [95], the cubic rectenna structure demonstrates higher energy-reception probability in ambient RFEH, due to the improved antenna diversity.

Improvements to antenna designs to increase the beamwidth included auxiliary parasitic patch elements to improve the WPT of a $2.4 \mathrm{GHz} 4 \times 1$ array [96]. A $6 \mathrm{GHz}$ Meshlike antenna with multiple beaming-regions was also proposed demonstrating multiple beams for each port [97], [98]. Multiport multi-rectifier surface rectennas and energy harvesting

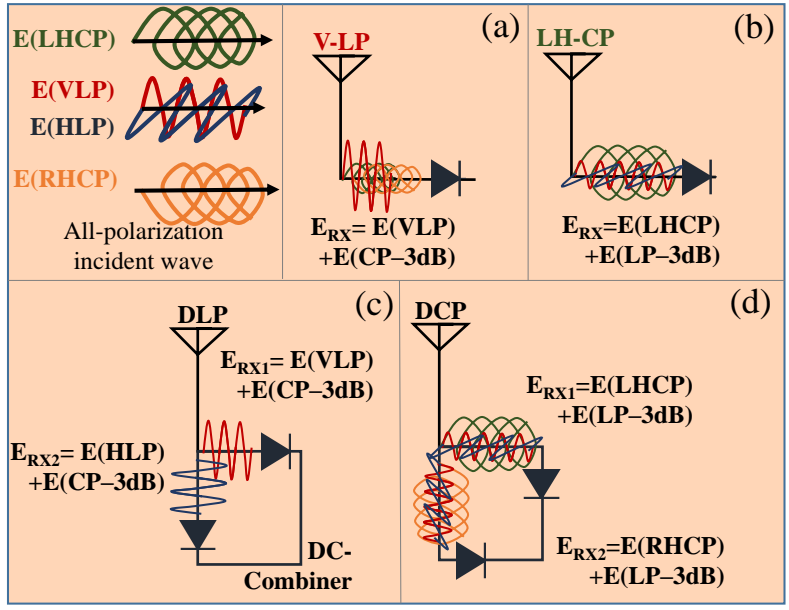

Fig. 6. Rectenna topologies based on antenna polarization, showing the total received power by each antenna from an all-polarized incident wave. (a): single LP antenna. (b): single CP. (c): Dual LP. (d): Dual CP.

antennas of omni-directional radiation patterns have been presented for multi-direction and multi-polarization RFEH [58], [60], [78], [79]. Multi-rectifier with beamforming matrices [99]-[101], and multi-port antenna arrays [98] have also been presented for high-gain, multi-direction energy harvesting. A comparison of RF-, Direct Current (DC)-, and hybrid power combining from multiple antennas have been presented in [102].

In conclusion, although high-gain antennas are preferred to improve the harvested power from low RF densities, highlydirectional receivers can be undesirable in applications with unknown transmitter direction, such as ambient RFEH, or WPT through an unknown propagation channel. In this effort, multiple methods of multi-beaming were proposed for multidirection high gain WPT and RFEH.

\section{B. Antenna Polarization for Maximum RFEH and WPT Eff- ciency}

Antenna polarization describes the motion of the field vectors referenced to the direction of propagation from the antenna. Polarization mismatch results in reduced transmission/reception between antennas even with main lobe direction alignment. For instance, no power is received if a vertically LP antenna is used for transmission, and a horizontally LP antenna is used for reception. In this section, reported approaches to maximize the wireless reception efficiency and avoid polarization mismatch losses are reviewed, in this regard, attention is paid to the antenna's ability to receive a wave (maintain higher gain) both through its primary and secondary polarizations, hence the FoM is the polarimetric gain, observed through the antenna's immunity to variation in the polarization angle of incidence, which can be quantitatively compared through the antenna's primary and secondary gains (e.g. left- and righthand $\mathrm{CP}$ ) being equally high. A summary of the proposed rectennas' architecture, in terms of polarization, is given in figure 6 with State-of-Art (SoA) examples in table IV.

In cellular communications, where linear-polarization alignment between the base-station and the mobile phone is very 

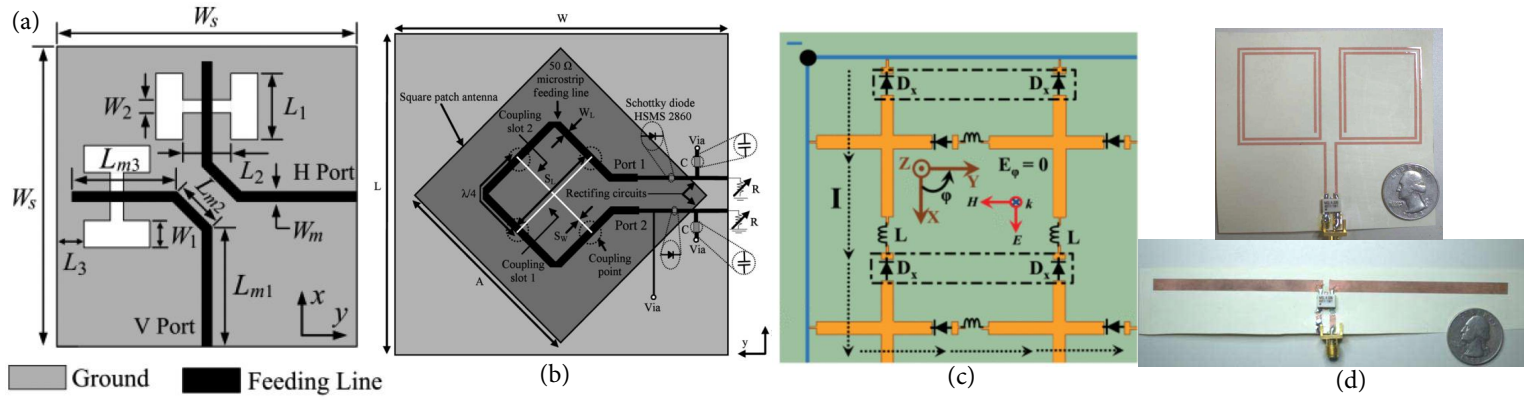

Fig. 7. Polarization independent rectennas: A: dual-LP slot [47], b: dual-CP slot [37], c: dual-LP cross-dipole array [58], d: dual antennas for harvesting near field H- (top) and E- (bottom) fields [105].

TABLE IV

COMPARISON OF RECTENNAS BASED ON THEIR POLARIZATION DIVERSITY

\begin{tabular}{|c|c|c|c|c|c|}
\hline Lit. & $\begin{array}{l}\text { Polariza- } \\
\text { tion }\end{array}$ & $\begin{array}{l}\text { Antenna } \\
\text { and Fre- } \\
\text { quency }\end{array}$ & $\begin{array}{l}\text { Primary } \\
\text { Gain } \\
\text { (FoM) }\end{array}$ & $\begin{array}{l}\text { Secondary } \\
\text { Gain } \\
\text { (FoM) }\end{array}$ & $\begin{array}{l}\text { Bandwidth } \\
\text { (MHz) }\end{array}$ \\
\hline 2018 & a: LP & 2.45 & Co-Pol & X-Pol & 50 \\
\hline [14] & & $\mathrm{GHz}$ & $7.3 \mathrm{dBi}$ & -15.2 & \\
\hline $\begin{array}{l}2018 \\
{[103]}\end{array}$ & $\mathrm{b}: \mathrm{CP}$ & $\begin{array}{l}5.8 \mathrm{GHz} \\
\text { Slot }\end{array}$ & $6 \mathrm{dBc}$ & $-14 \mathrm{dBc}$ & 1000 \\
\hline 2018 & c: DLP & $2.4 \mathrm{GHz}$ & H-LP & V-LP & 140 \\
\hline [104] & & & $7.45 \mathrm{dBi}$ & $7.63 \mathrm{dBi}$ & \\
\hline $\begin{array}{l}2015 \\
{[59]}\end{array}$ & d: DCP & $\begin{array}{l}2.4 \mathrm{GHz} \\
\text { Slot }\end{array}$ & $7.9 \mathrm{dBc}$ & $7.9 \mathrm{dBc}$ & 700 \\
\hline
\end{tabular}

unlikely, base-station antennas have been designed to be dual-polarized [106], [107], or multi-polarized [108]; avoiding polarization-mismatch losses when being received by a phone's LP antenna, regardless of its angle. However, variation in a LP wave's polarization due to multi-path effects remain an unresolved issue. Based on the assumption of multipolarized mobile base-station, cellular RFEH antennas have been designed as LP antennas; as reported in most ambient RFEH literature [15], [28], [45], [54].

Circularly Polarized (CP) rectennas have been mainly proposed for WPT due to their relative immunity to being mispositioned [42], [50], [109]. CP antennas enable reception of CP radiation with the same direction of rotation (left- or right-hand-side $\mathrm{CP}$ ) without power losses, in addition to all LP waves with a $3 \mathrm{~dB}$ loss (50\% power loss) regardless of the polarization angle. Thus, multiple WPT rectennas employed $\mathrm{CP}$ antennas to achieve rotation-independence with a $\mathrm{CP}$ transmitter. CP rectennas have been reported for the $900 \mathrm{MHz}$, 2.4 [37], [110], and 5.8 GHz Industrial Scientific Medical (ISM)-bands [103], [109], [111] as well as for mmWave rectennas [50], [112]. CP antennas based on asymmetric geometry have been reported has been reported with widerbeam axial ratio to improve the immunity to mis-positioning in WPT applications [113] along with beam switching for improved angular coverage [101].

In RFEH from arbitrarily polarized waves, polarizationdiversity represents a potential solution to polarization mismatch losses [93]. Dual LP rectennas have been demonstrated using imbalanced slotted radiating elements [110], as well as slotted ground planes [114] in proximity fed antennas; rotated feed slots are used to achieve dual LP. Cross dipoles have also been reported for dual-LP rectennas for RFEH [54] along with dual-port patches [57]. It is expected that with dualLP, the antenna could receive a similar amount of power regardless of the polarization angle. For instance, a stable PCE has been achieved by a dual-LP patch while varying the polarization orientation by $360^{\circ}$ [115]. The dual-port/dualrectifier architecture has been widely reported in ambient RFEH or random-polarization in LP rectennas WPT [35], [39], [57], [116] and CP rectennas [24], [37], [42], [112].

All-polarization, also-known-as multi-polarization, has been presented for entirely overcoming polarization mismatch losses, enabling harvesting CP and LP waves [59], [104], [117], where the two dual polarization-orthogonal LP elements effectively harvest all LP and CP waves. To illustrate, the net vertical and horizontal voltages $\left(V_{V}\right.$ and $\left.V_{H}\right),(2)$, remain unchanged regardless of the polarization angle. A CP-wave "E" follows in (3) and (4) where the power is harvested twice (once by each element) resulting in full reception of the $\mathrm{CP}$ component [104], overcoming the $3 \mathrm{~dB}$ polarization mismatch loss. Finally, through DC-combining arbitrarily polarized incident waves can be harvested. The dual-port antenna in [118] achieves left- and right-hand CP and LP using a dualmode SIW cavity. Orthogonal Dual-LP and DCP were both reported to achieve similar net harvested power regardless of the incident polarization after combining the power from both ports [59], [104]. Figure 7 shows the geometry of reported all-polarization rectennas.

$$
\begin{gathered}
P_{R X}\left(\varphi=90^{\circ}\right)=\frac{V_{V}^{2}}{2 Z_{0}}=P_{R X}\left(\varphi=0^{\circ}\right)=\frac{V_{H}^{2}}{2 Z_{0}} \\
E_{L H C P}=\frac{1}{\sqrt{2}}\left(E_{x}+j E_{y}\right) \\
E_{R H C P}=\frac{1}{\sqrt{2}}\left(E_{x}-j E_{y}\right)
\end{gathered}
$$

Polarization independent surfaces have been presented using a cascaded cross-dipole rectenna array [58], meta-material surface rectenna [78], and receiving meta-material antennas with a dummy resistive-load [79], [83] or a microstrip-transformer connected to a $50 \Omega \mathrm{RF}$ power meter [119]. A frequency selective surface has also been used to harvest arbitrarily polarized waves [120]. Surface rectennas have been reported at a variety of frequencies and 
Dual dipoles have also been utilized to achieve allpolarization operation at Ultra-high Frequency (UHF) (0.75 - $0.95 \mathrm{GHz}$ ), receiving up to $13 \mathrm{~dB}$ higher RF power by using only 4-dipole elements compared to a single dipole rectenna [117]. Dual orthogonal slotting of the patch's ground plane has been reported for the aperture feed of dual LP rectennas [59], [104], harmonics rejection has also been achieved due to the slotted feed in [59] omitting the need for an independent filter.

Where all-polarization is achieved using dual antenna feeds, the rectifier has been used to combine the incident arbitrarilypolarized wave with the two ports connected as a signal and ground to the voltage doubler or shunt diode [104], [121]. An alternative topology has been presented in [104], [117] where every output is rectified independently with DC combining. A modified charge pump has been presented in [116] to mitigate the effect of imbalance between the vertically and horizontally LP incident power.

To summarize, in WPT applications with a dedicated power source, CP is preferred due to the improved WPT efficiency regardless of antenna's polarization angle. On the other hand, in multi-source harvesting, specifically from ambient sources, all-polarization antennas can achieve better overall reception and maximum portability; a multi-port/multi-rectifier architecture is required to combine the all-polarization power at RF or DC.

\section{CONCLUSION}

In this paper, recent advances in antenna design for RF energy harvesting and WPT are reviewed, presenting a standard categorization of RFEH and WPT antenna design, not presented previously in literature. The three fundamental antenna requirements for achieving high RF to DC efficiency have been identified as:

1) Antenna-rectifier impedance bandwidth at RFEH and WPT bands of interest.

2) Main-lobe alignment between the transmitter and receiver in WPT from a dedicated feed.

3) Polarization match between the rectenna and the incident wave, regardless of the angle and position.

Based on their impedance, rectennas have been classified into $50 \Omega$ and rectifier-conjugate, rectennas, with emphasis on the impedance matching across different frequency bands and loads, along with the efficiency of each matching approach.

The radiation properties, from a directivity and polarization perspective, have been reviewed in state-of-art rectennas. Methods of improving the gain through beamforming and packaging to overcome the narrow beamwidth were reviewed. Finally, CP rectennas for WPT were reviewed along with various implementations to achieve polarization-independent reception both for WPT and RFEH.

\section{REFERENCES}

[1] N. Tesla, "The transmission of electrical energy without wires as a means for furthering peace," Electrical World and Engineer, pp. 21 24, January, 1905.

[2] W. Brown, "The history of power transmission by radio waves," IEEE Trans. Microw. Theory Techn., vol. 32, 9, pp. 1230 - 1242, 1984.
[3] J. Garnica, R. A. Chinga, and J. Lin, "Wireless power transmission: From far field to near field," Proceedings of the IEEE, vol. 101, 6, pp. 1321 - 1331, 2013.

[4] H. J. Visser and R. J. M. Vullers, "Rf energy harvesting and transport for wireless sensor network applications: Principles and requirements," Proceedings of the IEEE, vol. 101, 6, pp. 1410 - 1423, 2013.

[5] X. Lu, P. Wang, D. Niyato, D. I. Kim, and Z. Han, "Wireless networks with rf energy harvesting: A contemporary survey," IEEE Communications Surveys \& Tutorials, vol. 17, 2, pp. 757 - 789, 2015.

[6] C. R. Valenta and G. D. Durgin, "Harvesting wireless power: Survey of energy-harvester conversion efficiency in far-field, wireless power transfer systems," IEEE Microwave Magazine, vol. 15, 4, pp. 108-120, 2014.

[7] U. Guler and M. Ghovanloo, "Power management in wireless powersipping devices: A survey," IEEE Circuits and Systems Magazine, vol. 17, 4, pp. 64-82, 2015.

[8] S. K. Divakaran, D. D. Krishna, and Nasimuddin, "Rf energy harvesting systems: An overview and design issues," International Journal of $R F$ and Microwave Computer-Aided Engineering, vol. 29, 1, pp. 1 - 15, 2018.

[9] T. Soyata, L. Copeland, and W. Heinzelman, "Rf energy harvesting for embedded systems: A survey of tradeoffs and methodology," IEEE Circuits and Systems Magazine, vol. 16, 1, pp. 22 - 57, 2016.

[10] M. Cansiza, D. Altinel, and G. K. Kurt, "Efficiency in rf energy harvesting systems: A comprehensive review," Energy, vol. 174, pp. 292-309, 2019.

[11] G. Breed, "Theres nothing magic about 50 ohms," High Frequency Electronics, pp. 6 - 7, 2007.

[12] V. Kuhn, C. Lahuec, F. Seguin, and C. Person, "A multi-band stacked rf energy harvester with rf-to-dc efficiency up to 8463, 5, pp. 1768 1778, 2015.

[13] C. Song, Y. Huang, P. Carter, J. Zhou, S. Yuan, Q. Xu, and M. Kod, "A novel six-band dual $\mathrm{cp}$ rectenna using improved impedance matching technique for ambient rf energy harvesting," IEEE Trans. on Antennas Propag., vol. 64, 7, pp. $3160-3171,2016$.

[14] S.-E. Adami, P. Proynov, G. S. Hilton, G. Yang, C. Zhang, D. Zhu, Y. Li, S. P. Beeby, I. J. Craddock, and B. H. Stark, "A flexible 2.45-ghz power harvesting wristband with net system output from $-24.3 \mathrm{dbm}$ of rf power," IEEE Trans. Microw. Theory Techn., 2018.

[15] M. Pinuela, P. D. Mitcheson, and S. Lucyszyn, "Ambient rf energy harvesting in urban and semi-urban environments," IEEE Trans. Microw. Theory Techn., vol. 61, 7, pp. 2715 - 2726, 2013.

[16] V. Palazzi, J. Hester, J. Bito, F. Alimenti, C. Kalialakis, A. Collado, P. Mezzanotte, A. Georgiadis, L. Roselli, and M. M. Tentzeris, "A novel ultra-lightweight multiband rectenna on paper for rf energy harvesting in the next generation lte bands," IEEE Microw. Theory Techn., vol. 66, 1, pp. $366-379,2018$.

[17] H. Sun, Y. xin Guo, M. He, and Z. Zhong, "A dual-band rectenna using broadband yagi antenna array for ambient rf power harvesting," IEEE Antennas and Wireless Propagation Letters, vol. 12, pp. 918 - 921, 2013.

[18] M. Stoopman, S. Keyrouz, H. J. Visser, K. Philips, and W. A. Serdijn, "Co-design of a cmos rectifier and small loop antenna for highly sensitive rf energy harvesters," IEEE Journal of Solid-State Circuits, vol. 49, 3, pp. $622-634,2014$.

[19] H. Miyagoshi, K. Noguchi, K. Itoh, and J. Ida, "High-impedance wideband folded dipole antenna for energy harvesting applications," in 2014 International Symposium on Antennas Propag. Conference Proceedings, 2014.

[20] C. Song, Y. Huang, J. Zhou, P. Carter, S. Yuan, Q. Xu, and Z. Fei, "Matching network elimination in broadband rectennas for high efficiency wireless power transfer and energy harvesting," IEEE Trans. on Industrial Electronics, vol. 64, 5, pp. 3950 - 3961, 2017.

[21] B. L. Pham and A.-V. Pham, "Triple bands antenna and high efficiency rectifier design for rf energy harvesting at 900, 1900 and $2400 \mathrm{mhz}$," in 2013 IEEE MTT-S International Microwave Symposium Digest (MTT), 2013.

[22] S. Shen, C.-Y. Chiu, and R. D. Murch, "A dual-port triple-band 1probe microstrip patch rectenna for ambient rf energy harvesting," IEEE Antennas and Wireless Propagation Letters, vol. 16, pp. 3071 - 3074, 2017.

[23] T. Matsunaga, E. Nishiyama, and I. Toyoda, "5.8-ghz stacked differential rectenna suitable for large-scale rectenna arrays with dc connection," IEEE Trans. on Antennas Propag., vol. 63, 12, pp. 5944 $-5949,2015$.
576 
[24] Y.-J. Ren and K. Chang, "5.8-ghz circularly polarized dual-diode rectenna and rectenna array for microwave power transmission," IEEE Trans. Microw. Theory Techn., vol. 54, 4, pp. 1495 - 1502, 2006.

[25] P. Kamalinejad, C. Mahapatra, Z. Sheng, S. Mirabbasi, V. C. M. Leung, and Y. L. Guan, "Novel design of 2.45-ghz rectenna element and array for wireless power transmission," IEEE Access, vol. 7, pp. $28356-$ $28362,2019$.

[26] A. M. Jie, Nasimuddin, M. F. Karim, and K. T. Chandrasekaran, "A wide-angle circularly polarized tapered-slit-patch antenna with a compact rectifier for energy-harvesting systems [antenna applications corner]," IEEE Antennas Propag. Magazine, vol. 61, 2, pp. 94 - 111, 2019.

[27] S. Yang and J. Kim, "Wireless power transmission using dipole rectennas made on flexible cellulose membrane," IET Microwaves, Antennas \& Propagation, vol. 6, 7, pp. 756 - 760, 2012.

[28] S. Shen, Y. Zhang, C.-Y. Chiu, and R. Murch, "An ambient rf energy harvesting system where the number of antenna ports is dependent on frequency," IEEE Trans. Microw. Theory Techn., vol. Early Access, pp. $1-12,2019$.

[29] Y. Tawk, J. Costantine, F. Ayoub, and C. G. Christodoulou, "A communicating antenna array with a dual-energy harvesting functionality [wireless corner]," IEEE Antennas Propag. Magazine, vol. 60, 2, pp. $132-144,2018$.

[30] J.-K. Huang, W.-T. Hung, T.-H. Cheng, and S.-Y. Chen, "A 2.45ghz high-efficiency loop-shaped pifa rectenna for portable devices and wireless sensors," in 2015 IEEE International Symposium on Antennas Propag. \& USNC/URSI National Radio Science Meeting, 2015.

[31] C. Liu, Y.-X. Guo, H. Sun, and S. Xiao, "Design and safety considerations of an implantable rectenna for far-field wireless power transfer," IEEE Trans. on Antennas Propag., vol. 62, 11, pp. 5798 - 5806, 2014.

[32] T. Sakamoto, Y. Ushijima, E. Nishiyama, M. Aikawa, and I. Toyoda, "5.8-ghz series/parallel connected rectenna array using expandable differential rectenna units," IEEE Trans. on Antennas Propag., vol. 61, 9, pp. $4872-4875,2013$.

[33] A. Okba, A. Takacs, and H. Aubert, "Compact rectennas for ultralow-power wireless transmission applications," IEEE Trans. Microw. Theory Techn., vol. 67, 5, pp. 1697 - 1707, 2019.

[34] J. Zhang, X. Bai, W. Han, B. Zhao, L. Xu, and J. Wei, "The design of radio frequency energy harvesting and radio frequencybased wireless power transfer system for batteryless selfsustaining applications," International Journal of RF and Microwave Computer-Aided Engineering, vol. 29, 1, pp. 1-13, 2018.

[35] Y. Shi, Y. Fan, Y. Li, L. Yang, and M. Wang, "An efficient broadband slotted rectenna for wireless power transfer at lte band," IEEE Trans. on Antennas Propag., vol. Early Access, pp. 1 - 1, 2018.

[36] M.-J. Nie, X.-X. Yang, G.-N. Tan, and B. Han, "A compact 2.45ghz broadband rectenna using grounded coplanar waveguide," IEEE Antennas and Wireless Propagation Letters, vol. 14, pp. 986 - 989, 2015.

[37] Z. Harouni, L. Cirio, L. Osman, A. Gharsallah, and O. Picon, "A dual circularly polarized 2.45 -ghz rectenna for wireless power transmission," IEEE Antennas and Wireless Propagation Letters, vol. 10, pp. 306 309, 2011.

[38] V. Palazzi, M. D. Prete, and M. Fantuzzi, "Scavenging for energy: A rectenna design for wireless energy harvesting in uhf mobile telephony bands," IEEE Microwave Magazine, vol. 18, 1, pp. 91 - 99, 2017.

[39] M. Mattsson, C. I. Kolitsidas, and B. L. G. Jonsson, "Dual-band dualpolarized full-wave rectenna based on differential field sampling," IEEE Antennas and Wireless Propagation Letters, vol. 17, 6, pp. 956 - 959, 2018.

[40] M. Wagih, A. S. Weddell, and S. Beeby, "Millimeter-wave textile antenna for on-body rf energy harvesting in future $5 \mathrm{~g}$ networks," in 2019 IEEE Wireless Power Transfer Conference (WPTC), 2019.

[41] R. M. E. Khosht, M. A. E. Feshawy, M. A. E. Shorbagy, M. N. Farag, A. E. E. Said, H. F. Hammad, and A. T. Abdel-Hamid, "A foldable textile-based broadband archimedean spiral rectenna for $\mathrm{rf}$ energy harvesting," in 2016 16th Mediterranean Microwave Symposium (MMS), 2016.

[42] J. Hagerty, F. Helmbrecht, W. McCalpin, R. Zane, and Z. Popovic, "Recycling ambient microwave energy with broad-band rectenna arrays," IEEE Trans. Microw. Theory Techn., vol. 52, 3, pp. 1014 - 1024, 2002.

[43] M. Arrawatia, M. S. Baghini, and G. Kumar, "Broadband bent triangular omnidirectional antenna for rf energy harvesting," IEEE Antennas and Wireless Propagation Letters, vol. 15, pp. 36 - 39, 2015.

[44] M. Fantuzzi, D. Masotti, and A. Costanzo, "A novel integrated uwbuhf one-port antenna for localization and energy harvesting," IEEE Trans. on Antennas Propag., vol. 63, 9, pp. 3839 - 3848, 2015.
[45] S. Shen, C.-Y. Chiu, and R. D. Murch, "Multiport pixel rectenna for ambient rf energy harvesting," IEEE Trans. on Antennas Propag., vol. 66, 2, pp. $644-656,2018$.

[46] Z. Hameed and K. Moez, "A 3.2 v -15 dbm adaptive threshold-voltage compensated rf energy harvester in $130 \mathrm{~nm}$ cmos," IEEE Trans. on Circuits and Systems I: Regular Papers, vol. 62, 4, pp. 948 - 958 , 2015.

[47] H. Sun and W. Geyi, "A new rectenna with all-polarization-receiving capability for wireless power transmission," IEEE Antennas and Wireless Propagation Letters, vol. 15, pp. 814 - 817, 2016.

[48] J. Kimionis, M. Isakov, B. S. Koh, A. Georgiadis, and M. M. Tentzeris, "3d-printed origami packaging with inkjet-printed antennas for rf harvesting sensors," IEEE Trans. Microw. Theory Techn., vol. 63, 12, pp. $4521-4532,2015$.

[49] J. Bito, V. Palazzi, J. Hester, R. Bahr, F. Alimenti, P. Mezzanotte, L. Roselli, and M. M. Tentzeris, "Millimeter-wave ink-jet printed rf energy harvester for next generation flexible electronics," in 2017 IEEE Wireless Power Transfer Conference (WPTC), 2017.

[50] S. Ladan, A. B. Guntupalli, and K. Wu, "A high-efficiency $24 \mathrm{ghz}$ rectenna development towards millimeter-wave energy harvesting and wireless power transmission," IEEE Trans. On Circuits And Systems, vol. 61, 12, pp. 3358 - 3366, 2014

[51] Y.-S. Chen and C.-W. Chiu, "Maximum achievable power conversion efficiency obtained through an optimized rectenna structure for rf energy harvesting," IEEE Trans. on Antennas Propag., vol. 65, 5, pp. 2305 - 2317, 2017.

[52] S. Chandravanshi, S. S. Sarma, and M. J. Akhtar, "Design of triple band differential rectenna for rf energy harvesting," IEEE Trans. on Antennas Propag., vol. 66, 6, pp. 2716 - 2726, 2018.

[53] H. Sun and W. Geyi, "A new rectenna using beamwidth-enhanced antenna array for rf power harvesting applications," IEEE Antennas and Wireless Propagation Letters, vol. 16, pp. 1451 - 1454, 2016.

[54] C. Song, Y. Huang, J. Zhou, J. Zhang, S. Yuan, and P. Carter, "A highefficiency broadband rectenna for ambient wireless energy harvesting," IEEE Trans. on Antennas Propag., vol. 63, 8, pp. 3486-3495, 2015.

[55] D. Wang, X. A. Nghiem, and R. Negra, "Design of a $57 \%$ bandwidth microwave rectifier for powering application," in 2014 IEEE Wireless Power Transfer Conference, 2014.

[56] Q. Awais, Y. Jin, H. T. Chattha, M. Jamil, H. Qiang, and B. A Khawaja, "A compact rectenna system with high conversion efficiency for wireless energy harvesting," IEEE Access, vol. 6, pp. 35857 $35866,2018$.

[57] C. Song, Y. Huang, P. Carter, J. Zhou, S. D. Joseph, and G. Li, "Novel compact and broadband frequency-selectable rectennas for a wide input-power and load impedance range," IEEE Trans. on Antennas Propag., vol. 66, 7, pp. 3306 - 3316, 2018.

[58] A. Z. Ashoor and O. M. Ramahi, "Polarization-independent crossdipole energy harvesting surface," IEEE Trans. Microw. Theory Techn., 2019.

[59] J.-H. Chou, D.-B. Lin, K.-L. Weng, and H.-J. Li, "All polarization receiving rectenna with harmonic rejection property for wireless power transmission," IEEE Trans. on Antennas Propag., vol. 62, 10, pp. 5242 - 5249, 2014

[60] T. S. Almoneef, F. Erkmen, and O. M. Ramahi, "Harvesting the energy of multi-polarized electromagnetic waves," Scientific Reports, vol. 7 , pp. $3354-3356,2017$.

[61] H. Takhedmit, L. Cirio, S. Bellal, D. Delcroix, and O. Picon, "Compact and efficient $2.45 \mathrm{ghz}$ circularly polarised shorted ring-slot rectenna," Electronics Letters, vol. 48, 5, pp. 253 - 254, 2015.

[62] M. A. Abouzied, K. Ravichandran, and E. Sanchez-Sinencio, "A fully integrated reconfigurable self-startup rf energy-harvesting system with storage capability," IEEE Journal of Solid-State Circuits, vol. 52, 3 , pp. $704-719,2017$.

[63] J. Kang, S. Rao, P. Chiang, and A. Natarajan, "Design and optimization of area-constrained wirelessly powered cmos uwb soc for localization applications," IEEE Trans. Microw. Theory Techn., vol. 64, 4, pp. 1042 $-1054,2016$.

[64] V. Marian, B. Allard, C. Vollaire, and J. Verdier, "Strategy for microwave energy harvesting from ambient field or a feeding source," IEEE Trans. on Power Electronics, vol. 27, 11, pp. 4481 - 4491, 2012.

[65] U. Muncuk, te Kubra Alemdar, J. D. Sarode, and K. R. Chowdhury, "Multiband ambient rf energy harvesting circuit design for enabling batteryless sensors and iot," IEEE Internet of Things Journal, vol. 5, 4, pp. $2700-2714,2018$.

[66] S. Shieh and M. Kamarei, "Fast start-up rf energy harvester design for gsm-900 uplink band," IEEE Trans. on Circuits and Systems II: Express Briefs, vol. 66, 4, pp. 582 - 586, 2019. 
[67] P. Lu, K. Huang, Y. Yang, F. Cheng, and L. Wu, "Frequency reconfigurable rectenna with an adaptive matching stub for microwave power transmission," IEEE Antennas and Wireless Propagation Letters, vol. Early Access, pp. 1 - 1, 2019.

[68] S. M. Asif, J. Hansen, M. S. Khan, S. D. Walden, M. O. Jensen, B. D. Braaten, and D. L. Ewert, "Design and in vivo test of a batteryless and fully wireless implantable asynchronous pacing system," IEEE Trans. on Biomedical Engineering, vol. 63, 5, pp. 1070 - 1081, 2018.

[69] W. Lin, R. W. Ziolkowski, and J. Huang, "Electrically small, low profile, highly efficient, huygens dipole rectennas for wirelessly powering internet-of-things (iot) devices," IEEE Trans. on Antennas Propag., vol. Early access, 2019.

[70] K. R. Sadagopan, J. Kang, Y. Ramadass, and A. Natarajan, "A cm-scale 2.4-ghz wireless energy harvester with nanowatt boost converter and antenna-rectifier resonance for wifi powering of sensor nodes," IEEE Journal of Solid-State Circuits, vol. 53, 12, pp. 3396 - 3406, 2018.

[71] M.-C. Tang, H. Wang, and R. W. Ziolkowski, "Design and testing of simple, electrically small, low-profile, huygens source antennas with broadside radiation performance," IEEE Trans. on Antennas Propag., vol. 64, 11, pp. 4607 - 4617, 2016.

[72] A. Y.-S. Jou, H. Pajouhi, R. Azadegan, and S. Mohammadi, "A cmos integrated rectenna for implantable applications," in 2016 IEEE MTT-S International Microwave Symposium (IMS), 2016.

[73] H. Rahmani and A. Babaakhani, "A $434 \mathrm{mhz}$ dual-mode power harvesting system with an on-chip coil in $180 \mathrm{~nm}$ cmos soi for mm-sized implants," in 2018 IEEE MTT-S International Microwave Symposium (IMS), 2018.

[74] B. Zhao, N.-C. Kuo, B. Liu, Y.-A. Li, L. Iotti, and A. M. Niknejad, "A $5.8 \mathrm{ghz}$ power-harvesting $116 \mu \mathrm{mx} 116 \mu \mathrm{m}$ "dielet" near-field radio with on-chip coil antenna," in 2018 IEEE International Solid - State Circuits Conference - (ISSCC), 2018.

[75] Y. Sun, D. Li, and A. Babakhani, "A wirelessly-powered i.460hz transmitter with on-chip antennas in i80nm cmos," in 2018 IEEE International Solid - State Circuits Conference - (ISSCC), 2018.

[76] G. Marrocco, "The art of uhf rfid antenna design: impedance-matching and size-reduction techniques," IEEE, vol. 50, 1, pp. 66 - 79, 2008.

[77] J. McSpadden, L. Fan, and K. Chang, "Design and experiments of a high-conversion-efficiency 5.8-ghz rectenna," IEEE Trans. Microw. Theory Techn., vol. 46, 12, pp. 2053 - 2060, 1998.

[78] H.-T. Zhong, X.-X. Yang, C. Tan, and K. Yu, "Triple-band polarizationinsensitive and wide-angle metamaterial array for electromagnetic energy harvesting," Appl. Phys. Lett., vol. 109, pp. 1 - 4, 2016.

[79] H.-T. Zhong, X.-X. Yang, X.-T. Song, Z.-Y. Guo, and F. Yu1, "Wideband metamaterial array with polarization-independent and wide incident angle for harvesting ambient electromagnetic energy and wireless power transfer," Appl. Phys. Lett., vol. 111, pp. 1 - 4, 2017.

[80] F. Erkmen, T. S. Almoneef, and O. M. Ramahi, "Electromagnetic energy harvesting using full-wave rectification," IEEE Trans. Microw. Theory Techn., vol. 65, 5, pp. 1843 - 1851, 2017.

[81] A. Takacs, H. Aubert, and S. Charlot, "Ultra-compact ku band rectenna," in 2015 IEEE MTT-S International Microwave Symposium, 2015 .

[82] S. Preradovic and N. Karmakar, "Chipless millimeter wave identification (mmid) tag at $30 \mathrm{ghz}$," in 2011 41st European Microwave Conference, 2011.

[83] T. S. Almoneefa and O. M. Ramahi, "Metamaterial electromagnetic energy harvester with near unity efficiency," Appl. Phys. Lett., vol. 106, pp. $1-4,2015$.

[84] A. S. Andrenko, X. Lin, and M. Zeng, "Outdoor rf spectral survey: A roadmap for ambient rf energy harvesting," in TENCON 2015 - 2015 IEEE Region 10 Conference, 2015.

[85] N. Shinohara and H. Matsumoto, "Experimental study of large rectenna array for microwave energy transmission," IEEE Trans. Microw. Theory Techn., vol. 46, 3, pp. 261 - 268, 1998.

[86] Y. Song, J. Wang, and X. Luo, "Design of a high gain quasi-yagi antenna and array for rectenna," in 2017 IEEE International Symposium on Antennas Propag. \& USNC/URSI National Radio Science Meeting, 2017.

[87] N. P. Basta, E. A. Falkenstein, and Z. Popovic, "Bow-tie rectenna arrays," in 2015 IEEE Wireless Power Transfer Conference (WPTC), 2015.

[88] T. S. Almoneef, F. Erkmen, M. A. Alotaibi, and O. M. Ramahi, "A new approach to microwave rectennas using tightly coupled antennas," IEEE Trans. on Antennas Propag., vol. 66, 4, pp. 1714 - 1724, 2018.

[89] Y. Liu, K. Huang, Y. Yang, and B. Zhang, "A low-profile lightweight circularly polarized rectenna array based on coplanar waveguide," IEEE
Antennas and Wireless Propagation Letters, vol. 17, 9, pp. 1659 - 1663, 2018.

[90] Y. Yang, L. Li, J. Li, Y. Liu, B. Zhang, H. Zhu, and K. Huang, "A circularly polarized rectenna array based on substrate integrated waveguide structure with harmonic suppression," IEEE Antennas and Wireless Propagation Letters, vol. 17, 4, pp. 684 - 688, 2018.

[91] D.-Y. Kim, J. W. Lee, T. K. Lee, and C. S. Cho, "Design of siw cavity-backed circular-polarized antennas using two different feeding transitions," IEEE Trans. on Antennas Propag., vol. 59, 4, pp. 1398 1403, 2011.

[92] G. Q. Luo, X. H. Zhang, L. X. Dong, W. J. Li, and L. L. Sun, "A gain enhanced cavity backed slot antenna using high order cavity resonance," Journal of Electromagnetic Waves and Applications, vol. 25, pp. 1273 - 1279, 2011.

[93] O. Bjorkqvist, O. Dahlberg, G. Silver, C. Kolitsidas, O. QuevedoTeruel, and B. Jonsson, "Wireless sensor network utilizing radiofrequency energy harvesting for smart building applications [education corner]," IEEE Antennas Propag. Mag., vol. 60, 5, pp. 124 - 136, 2018.

[94] Y.-S. Chen and J.-W. You, "A scalable and multidirectional rectenna system for rf energy harvesting," IEEE Trans. on Components, Packaging and Manufacturing Technology, vol. 8, 12, pp. 2060 - 2072, 2018.

[95] D. H. N. Bui, T.-P. Vuong, J. Verdier, B. Allard, and P. Benech, "Design and measurement of $3 \mathrm{~d}$ flexible antenna diversity for ambient rf energy scavenging in indoor scenarios," IEEE Access, vol. 7, pp. 17033 $17044,2019$.

[96] H. Sun and W. Geyi, "A new rectenna using beamwidth-enhanced antenna array for rf power harvesting applications," IEEE Antennas and Wireless Propagation Letters, vol. 16, pp. 1451 - 1454, 2016.

[97] Y.-Y. Hu and S. Sun, "Dual-polarized and multi-beam cross-mesh array antenna for rf energy harvesting applications," in 2018 IEEE International Symposium on Antennas Propag. \& USNC/URSI National Radio Science Meeting, 2018

[98] Y.-Y. Hu, S. Sun, H. Xu, and H. Sun, "Grid-array rectenna with wide angle coverage for effectively harvesting rf energy of low power density," IEEE Trans. Microw. Theory Techn., vol. 67, 1, pp. 402 413, 2019.

[99] E. Vandelle, P. L. Doan, D. H. N. Bui, T. P. Vuong, G. Ardila, K. Wu, and S. Hemour, "High gain isotropic rectenna," in 2017 IEEE Wireless Power Transfer Conference (WPTC), 2017.

[100] E. Vandelle, D. H. N. Bui, T.-P. Vuong, G. Ardila, K. Wu, and S. Hemour, "Harvesting ambient rf energy efficiently with optimal angular coverage," IEEE Trans. on Antennas Propag., vol. 67, 3, pp. 1862 - 1873, 2019.

[101] K. T. Chandrasekaran, N. Nasimuddin, A. Alphones, and M. F. Karim, "Compact circularly polarized beamswitching wireless power transfer system for ambient energy harvesting applications," Int. J. RF and Microw Computer-Aided Engineering, vol. 29, no. 1, pp. 1 - 10, 2017.

[102] D.-J. Lee, S.-J. Lee, I.-J. Hwang, W.-S. Lee, and J.-W. Yu, "Hybrid power combining rectenna array for wide incident angle coverage in rf energy transfer," IEEE Trans. Microw. Theory Techn., vol. 65, 9, pp. 3409 - 3418, 2017.

[103] Y. Yang, L. Li, J. Li, Y. Liu, B. Zhang, H. Zhu, and K. Huang, "A circularly polarized rectenna array based on substrate integrated waveguide structure with harmonic suppression," IEEE Antennas and Wireless Propagation Letters, vol. 17, 4, pp. 684 - 688, 2018.

[104] H. Sun and W. Geyi, "A new rectenna with all-polarization-receiving capability for wireless power transmission," IEEE Antennas and Wireless Propagation Letters, vol. 15, pp. 814 - 817, 2015.

[105] J. Bito, J. G. Hester, and M. M. Tentzeris, "Ambient rf energy harvesting from a two-way talk radio for flexible wearable wireless sensor devices utilizing inkjet printing technologies," IEEE Trans. Microw. Theory Techn., vol. 63, 12, pp. 4533-4543, 2015.

[106] X. Quan and R. Li, "A broadband dual-polarized omnidirectional antenna for base stations," IEEE Trans. on Antennas Propag., vol. 61, 2, pp. 943 - 947, 2013

[107] Y. Cui, R. Li, and H. Fu, "A broadband dual-polarized planar antenna for $2 \mathrm{~g} / 3 \mathrm{~g} / \mathrm{lte}$ base stations," IEEE Trans. on Antennas Propag., vol. 62, 9, pp. 4836 - 4840, 2014.

[108] K. R. Mahmoud and A. M. Montaser, "Performance of tri-band multipolarized array antenna for $5 \mathrm{~g}$ mobile base station adopting polarization and directivity control," IEEE Access, vol. 6, pp. 8682 - 8694, 2018.

[109] M. Ali, G. Yang, and R. Dougal, "Miniature circularly polarized rectenna with reduced out-of-band harmonics," IEEE Antennas and Wireless Propagation Letters, vol. 5, pp. 107 - 110, 2006. 
[110] T.-C. Yo, C.-M. Lee, C.-M. Hsu, and C.-H. Luo, "Compact circularly polarized rectenna with unbalanced circular slots," IEEE Trans. on Antennas Propag., vol. 56, 3, pp. 882 - 886, 2008.

[111] J. Heikkinen and M. Kivikoski, "A novel dual-frequency circularly polarized rectenna," IEEE Antennas and Wireless Propagation Letters, vol. 2 , pp. $330-333,2003$.

[112] R. Rasshofer, M. Thieme, and E. Biebl, "Circularly polarized millimeter-wave rectenna on silicon substrate," IEEE Antennas and Wireless Propagation Letters, vol. 46, 5, pp. 715 - 718, 1998.

[113] S. B. Vignesh, Nasimuddin, and A. Alphones, "Stubs-integratedmicrostrip antenna design for wide coverage of circularly polarised radiation," IET Microwaves, Antennas \& Propagation, vol. 11, no. 4, pp. $444-449,2017$.

[114] X. Lou and G.-M. Yang, "A dual linearly polarized rectenna using defected ground structure for wireless power transmission," IEEE Microwave and Wireless Components Letters, vol. 28, 9, pp. 828 830, 2018.

[115] F. Erkmen, T. S. Almoneef, and O. M. Ramahi, "Dual linear polarized cavitybacked patch rectenna with dc power management network for optimized wireless rf power transfer," Microwave and Optical Technology Letters, vol. 60, 3, pp. 713 - 717, 2017.

[116] H. Zhang, S.-P. Gao, W. Wu, and Y.-X. Guo, "Uneven-to-even power distribution for maintaining high efficiency of dual-linearly polarized rectenna," IEEE Microwave and Wireless Components Letters, vol. 28, 12, pp. 1119 - 1121, 2018.

[117] M. Fantuzzi, M. D. Prete, D. Masotti, and A. Costanzo, "Quasiisotropic rf energy harvester for autonomous long distance iot operations," in 2017 IEEE MTT-S International Microwave Symposium (IMS), 2017.

[118] Z.-C. Hao, K.-K. Fan, and H. Wang, "A planar polarizationreconfigurable antenna," IEEE Antennas and Wireless Propagation Letters, vol. 65, 4, pp. $1624-1632,2018$.

[119] B. Ghaderi, V. Nayyeri, M. Soleimani, and O. M. Ramahi, "Multipolarisation electromagnetic energy harvesting with high efficiency," IET Microwaves, Antennas \& Propagation, vol. 12, 15, pp. 2271 2275, 2018.

[120] S. Keyrouz, G. Perotto, and H. J. Visser, "Frequency selective surface for radio frequency energy harvesting applications," IET Microwaves, Antennas \& Propagation, vol. 8, 7, pp. 523 - 531, 2014.

[121] A. Georgiadis, G. V. Andia, and A. Collado, "Rectenna design and optimization using reciprocity theory and harmonic balance analysis for electromagnetic (em) energy harvesting," IEEE Antennas and Wireless Propagation Letters, vol. 9, pp. 444 - 446, 2017. 